\title{
The Fine Structure of Coatings on the Basis Ni-Al Formed by the Magnetron Method
}

\author{
Marina V. Fedorischeva ${ }^{1, \text { a) }}$, Victor P. Sergeev ${ }^{1,2, b)}$, Mark P. Kalashnikov ${ }^{1,2, c)}$, \\ and Andrei V. Voronov ${ }^{1, d)}$ \\ ${ }^{1}$ Institute of Strength Physics and Materials Science SB RAS, Tomsk, 634055, Russia \\ ${ }^{2}$ National Research Tomsk Polytechnic University, Tomsk, 634050, Russia \\ a) Corresponding author: fmw@ispms.tsc.ru \\ b)vserg@mail.tomsknet.ru \\ c)kmp1980@mail.ru \\ d) rets@ispms.tsc.ru
}

\begin{abstract}
Phase composition, fine structure and surface morphology of intermetallic coatings are investigated by X-ray analysis and TEM. It is shown that $\mathrm{Ni}_{3} \mathrm{Al}$ is the main phase of the intermetallic coating for all the investigated samples. There is a Ni-Al phase in the samples of the first type. Three types of grains, differing in size, are discovered in the structure of nanocrystalline coatings: dislocation free, dislocation, and fragmented. The internal stresses, obtained by TEM and X-ray analysis, have close values.
\end{abstract}

Keywords: phase composition, microstructure, intermetallide, grain size, magnetron deposition, ion implantation

\section{INTRODUCTION}

Intermetallic compounds $\mathrm{Ni}_{3} \mathrm{Al}$ and $\mathrm{Ni}-\mathrm{Al}$ have a number of unique properties and they are the objects of numerous investigations $[1,2]$. The interest to the intermetallic compound of nickel with aluminium and, in particular, to the intermetallide of $\mathrm{Ni}_{3} \mathrm{Al}$ as a constructional material is determined by the anomalous temperature dependence of its mechanical properties. It means that in the certain temperature interval when the temperature increases, mechanical properties do not decrease, and on the contrary, they increase. In pure metals, the resistance to deformation always decreases when the temperature increases. The $\mathrm{Ni}-\mathrm{Al}$ system, apart from solid solutions, has four equilibrium phases: $\mathrm{NiAl}_{3}$ ( $\varepsilon$-phase), $\mathrm{Ni}_{2} \mathrm{Al}_{3}$ ( $\delta$-phase), $\mathrm{NiAl}$ ( $\beta$-phase), $\mathrm{Ni}_{3} \mathrm{Al}$ ( $\gamma^{\prime}$-phase) and a non-equilibrium phase of $\mathrm{Ni}_{5} \mathrm{Al}_{3}$ [3]. Ni-Al (superstructure $\mathrm{B} 2$ ) and $\mathrm{Ni}_{3} \mathrm{Al}$ (superstructure $\mathrm{Ll}_{2}$ ) are the most promising for use as a coating [4].

Magnetron deposition is the most widespread and reliable deposition of the coating on the basis of $\mathrm{Ni}-\mathrm{Al}$ alloys. High-energy ion beams represent the effective modification way of the structural-phase condition and mechanical properties of the surface layer. It allows producing the coatings with higher mechanical properties. In [5] we closely investigated the effect of ionic-beam processing, substrate temperatures on the structural-phase state, nanohardness and wear resistance of the intermetallic coatings produced by magnetron deposition.

It is known [6] that in some cases alloying by the third element allows improving the material properties essentially. In the present work, we continue to study the technological parameter effect on the structural-phase state of the nanocrystalline intermetallide of $\mathrm{Ni}_{3} \mathrm{Al}$. Besides, the effect of the third element such as boron on the structure and mechanical properties of the intermetallic coatings are studied.

The effect of aluminum and boron ion implantation on the phase composition and a fine structure of the coating on the basis of the $\mathrm{Ni}-\mathrm{Al}$ system, obtained by the magnetron deposition method, are investigated in this work.

(C) 2014 AIP Publishing LLC 978-0-7354-1260-6/\$30.00 

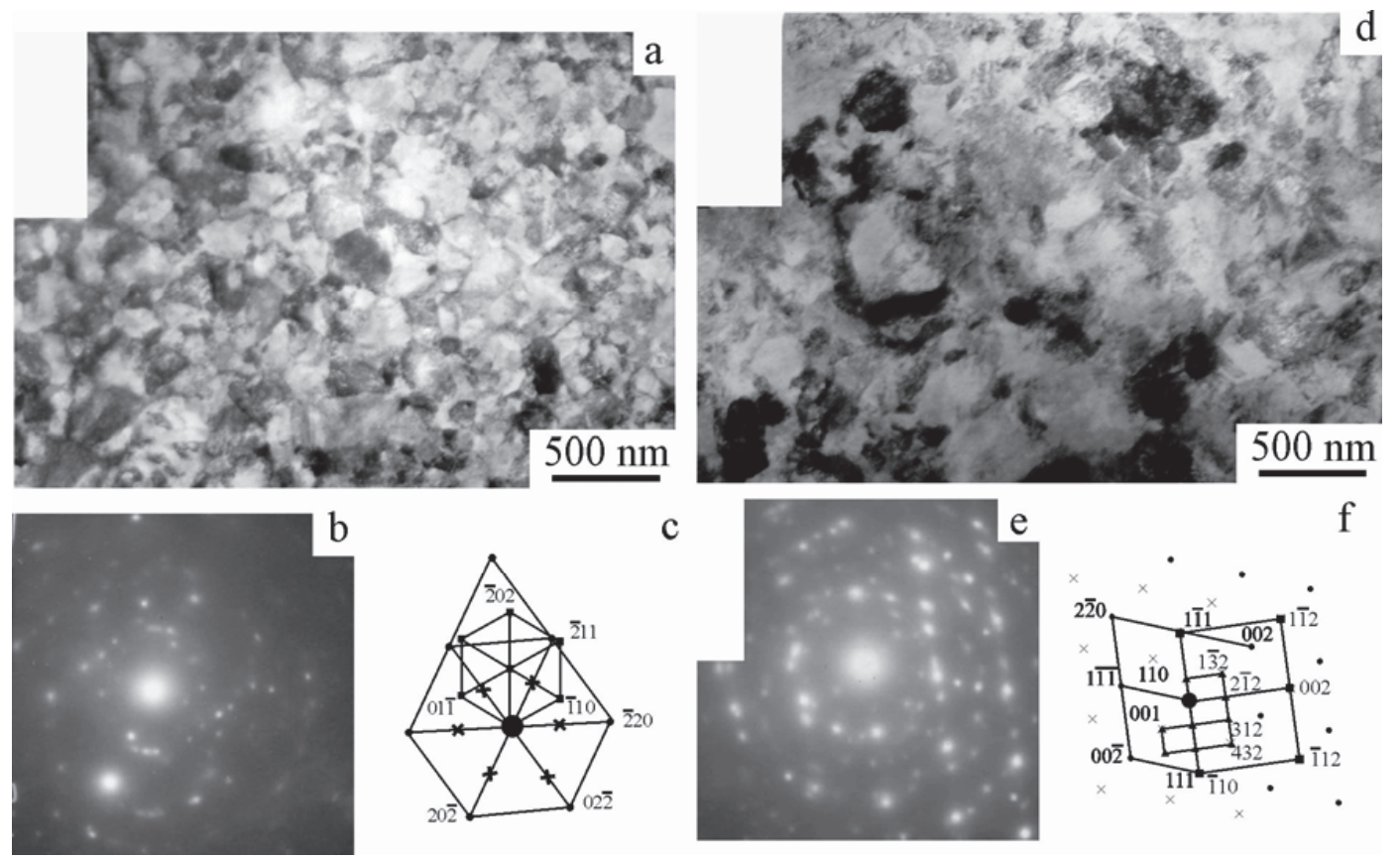

FIGURE 1. TEM image of the $\mathrm{Ni}_{3} \mathrm{Al}$ coatings, the first and second type: (a, d) the bright-field images; (b and e) the microdiffraction patterns; (c and f) the schemes of indexing. Dots denote $\mathrm{Ni}_{3} \mathrm{Al}(111)$; crosses, superstructural reflections of $\mathrm{Ni}_{3} \mathrm{Al}$; squares, $\mathrm{Ni}-\mathrm{Al}(111)$; triangles, $\mathrm{AlB}_{12}(420)$

\section{EXPERIMENTAL}

$\mathrm{Ni}_{3} \mathrm{Al}$ coatings were deposited by the KVANT magnetron sputtering system combined with an arc evaporator with aluminium cathode [7]. Ion implantation was accomplished using a DIANA-type device.

The phase composition and crystalline structure parameters of the intermetallic coatings were examined by X-ray. Internal stresses were the result of the analysis of X-ray line-broadening profiles and could be determined from the local changes in the lattice parameters. The stresses value was estimated as $\Delta d_{\max } / d$, where $\mathrm{d}$ was the lattice plane spacing. For cubical syngony $\Delta d / d=\Delta a / a, \sigma \cong(\Delta d / d) E$, where $E$ was the elasticity modulus, $\Delta d / d$ and $\Delta a / a$ depended on the direction at the anisotropic $E$ [8]. Meanwhile the direction was not taken into account in our case. Electron microscopy studies were carried out using the EM-125 electron microscope. Quantitative characteristics of the intermetallic coatings (dislocation density, curvature-torsion amplitude of the crystal lattice, and microstress) were obtained following the procedure described in detail in [9].

Two sets of the samples were prepared for study at different technological parameters: set 1, obtained by magnetron deposition with a substrate heated up to $600 \mathrm{~K}$ using a spiral, and set 2, obtained in the same manner with a subsequent aluminum and boron implantation.

TABLE 1. Structure characteristic of the coating on the basis of $\mathrm{Ni}-\mathrm{Al}$

\begin{tabular}{ccccccc}
\hline $\begin{array}{c}\text { The Type } \\
\text { of Samples }\end{array}$ & $\begin{array}{c}\text { The } \\
\text { Phases }\end{array}$ & $\begin{array}{c}\text { The Grain } \\
\text { Size, } \mathbf{n m}\end{array}$ & $\begin{array}{c}\text { The Volume } \\
\text { Fraction of } \\
\text { Phases }\end{array}$ & $\begin{array}{c}\text { The Internal } \\
\text { Stresses (TEM) } \boldsymbol{\sigma}, \\
\text { MPa }\end{array}$ & $\begin{array}{c}\text { The Internal } \\
\text { Stresses (X-ray) } \\
\boldsymbol{\sigma}, \mathbf{M P a}\end{array}$ & $\begin{array}{c}\text { The Average } \\
\text { Dislocation } \\
\text { Density } \mathbf{1} / \mathbf{c m}^{2}\end{array}$ \\
\hline \multirow{2}{*}{$\mathrm{I}$} & $\mathrm{Ni}_{3} \mathrm{Al}$ & $150 \pm 7$ & 0.98 & $420 \pm 20$ & $400 \pm 20$ & $4.3 \times 10^{10}$ \\
\cline { 2 - 7 } & $\mathrm{NiAl}$ & $50 \pm 3$ & 0.2 & - & - & - \\
\hline \multirow{2}{*}{$\mathrm{II}$} & $\mathrm{Ni}_{3} \mathrm{Al}$ & $210 \pm 10$ & 0.97 & $370 \pm 15$ & $400 \pm 20$ & $3.2 \times 10^{10}$ \\
\hline & $\mathrm{NiAl}^{2}$ & $75 \pm 4$ & 1.5 & - & - & - \\
\hline & $\mathrm{AlB}_{12}$ & $160 \pm 30$ & 1.5 & - & - & - \\
\hline
\end{tabular}




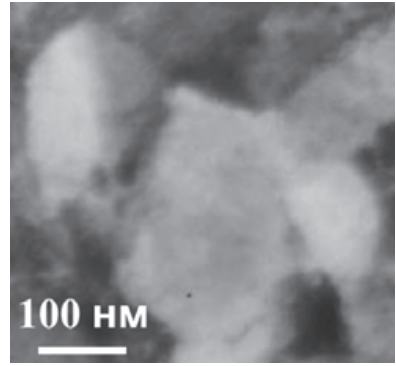

(a)

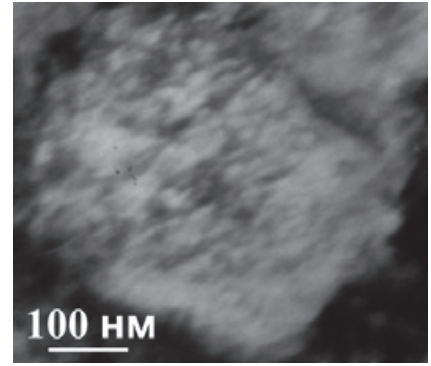

(b)

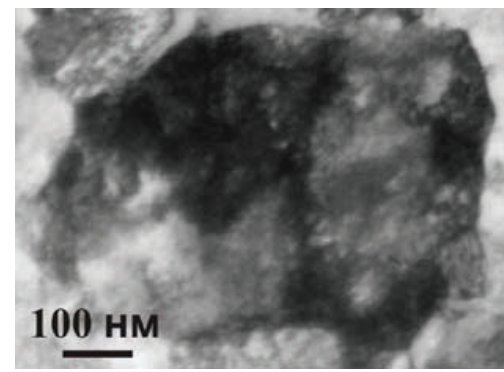

(c)

FIGURE 2. TEM images of the grains with different types: (a) dislocation free grains; (b) dislocation grains;

(c) fragmented grains

\section{RESULTS AND DISCUSSION}

Figure 1 shows TEM images of the coatings, the first and second types. As it can be seen, there are two phases in the coatings: the basic $\mathrm{Ni}_{3} \mathrm{Al}$ phase with $\mathrm{L}_{2}$ superstructure and the NiAl phase with $\mathrm{B} 2$ superstructure. The $\mathrm{Ni}_{3} \mathrm{Al}$ phase consists of rather large particles $(150 \mathrm{~nm})$. The NiAl particles are round; they are localized in the grain joints and along the grain boundaries.

The average size of the particles of this phase is $50 \mathrm{~nm}$. The quantitative data on the corresponding phase composition are given in Table 1. In the second type of the coatings, implanted by $\mathrm{Al}$ and $\mathrm{B}$ ions, the average grain size is slightly higher - about $210 \mathrm{~nm}$ for $\mathrm{Ni}_{3} \mathrm{Al}$ grains and $75 \mathrm{~nm}$ for NiAl grains. The lamellar inclusions of the $\mathrm{AlB}_{12}$ phase are located along the boundaries of the $\mathrm{Ni}_{3} \mathrm{Al}$ phase. It is found by TEM that the $\mathrm{Ni}_{3} \mathrm{Al}$ phase consists of three types of grains: dislocation free grains (DFGs), dislocation grains (DGs), and fragmented grains (FGs) differing in size (Fig. 2). The smallest grains are dislocation-free, the largest ones are fragmented. The examples of TEM images of the grain size are shown in Fig. 2.

Figure 3 shows the grain size distributions in the coating of the first and the second types. It can be seen that the existence interval of all the grain types significantly expands in the coatings of the second type. In the coatings of the first type, the existence area of dislocation-free grains is in the range of 40-180 nm, while in the coatings of the second type they are from 40 to $280 \mathrm{~nm}$. The most probable value of the grain size in the coating of the first type is $60 \mathrm{~nm}$, for the coating of the second type it is $120 \mathrm{~nm}$.

Koneva was the first who discovered such regularity for the pure monocrystalline metallic samples of $\mathrm{Cu}, \mathrm{Ni}$, and $\mathrm{CuAlO}$ [10]. That regularity was observed for the first time in the ordered nanocrystalline alloys studied in this work.

We measure the scalar density of the dislocations in $\mathrm{Ni}_{3} \mathrm{Al}$ grains both as the material average $\langle\rho\rangle$, and as the average value of the grains of different types.
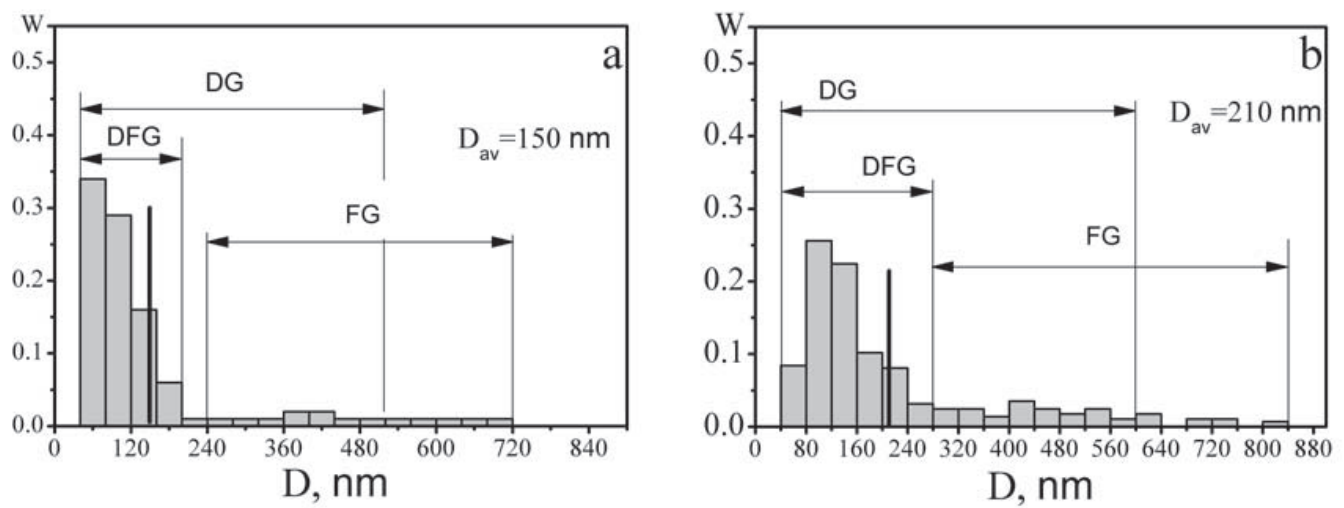

FIGURE 3. The grain size distributions of $\mathrm{Ni}_{3} \mathrm{Al}$ in the samples of the first type $\mathrm{I}(\mathrm{a})$ and the second type II (b) 
The resulting data are also given in Table 1. As it can be seen from the Table 1, the sample of the first type has virtually the same scalar density of dislocations in the grains with DG and FG substructures. The boron and aluminum implantation lowers the value of the scalar density of dislocations, both for the whole material and inside the grains of different types. In addition, it should be noted that the dislocation grains has the largest density of dislocations.

It means that partial etching of the material occurs in the process of implantation. It is known that the accumulation of high scalar density of dislocations, organized in the substructure of the material (chaotic, reticulated, cellular, fragmented), produces shear stress, i.e., the field of stress produced by the dislocation structure.

The value of shear stress is determined using the method described in $[10,11]$. Using the value of $\rho$, internal stress fields $\sigma$ in the material of the coatings are measured. Also, the internal stresses are determined using the linebroadening profiles by the X-ray method. They are $400 \mathrm{~nm}$ for all types of the samples. The corresponding data are listed in Table 1. It can be seen that the internal stresses, determined by X-ray and TEM, are close.

\section{CONCLUSION}

Using the $\mathrm{X}$-ray and TEM analyses it is established that there are intermetallic $\mathrm{Ni}_{3} \mathrm{Al}$ and $\mathrm{NiAl}$ in the coatings of the first type and $\mathrm{Ni}_{3} \mathrm{Al}, \mathrm{NiAl}$ and $\mathrm{AlB}_{12}$ in the coatings of the second type.

Three types of grains differing in size are discovered in the structure of the nanocrystalline coatings: dislocation free, dislocation, and fragmented. The internal stresses, obtained by the TEM and X-ray analyses, have close values.

\section{ACKNOWLEDGEMENTS}

The work was supported within the scope of the basic scientific research of state academies of sciences for 2013-2020, performed within the scope of the state task "Science NRTPU"

\section{REFERENCES}

1. C. T. Liu and D. P. Pore, in Intermetallic Compounds, Principles and Practice (Wiley, 1994), Vol. 3, p. 17.

2. D. B. Miracle and R. Darolia, in Intermetallic Compounds, Principles and Practice (Wiley, 1994), Vol. 3, p. 54.

3. N. S. Stoloff, Int. Mater. Rev. 34(4), 153 (1989).

4. H. Gleiter, Nanostruct. Mater. 6 (1995).

5. M. V. Fedorischeva, V. P. Sergeev, N. A. Popova, and E. V. Kozlov, Mater. Sci. Eng. A 483-484, 644 (2008).

6. E. V. Kozlov, M. V. Fedorishcheva, E. L. Nikonenko, and N. A. Koneva, Bull. Russ. Acad. Sci.: Phys. 73, 1101 (2009).

7. V V. P. Sergeev, V. P. Yanovsky, Yu. N. Paraev, S. A. Kozlov, and S. A. Zhuravlyov, Fiz. Mezomekh. 7(Spec. Iss.), 333 (2004).

8. Y. S. Umansky, Y. Skakov, A. N. Ivanov, and L. N. Rastorgouev, Crystallography, X-ray and Electron Microscopy (Metallurgy, Moscow, 1982).

9 N. A. Koneva, L. I. Trishkina, A. N. Zhdanov, O. B. Perevalova, N. A. Popova and E. V. Kozlov, Phys. Mesomech. 9(3-4), 87 (2006).

10. Y. R. Kolobov, E. N. Kablov, et al., The Structure and Properties of Intermetallic Nanophase Materials with Hardening (Publ. House MISA, Moscow, 2008).

11. E. V. Kozlov, N. A. Koneva, A. N. Zhdanov, N. A. Popova, and Yu. F. Ivanov, Fiz. Mezomekh. 7(4), 93 (2004). 